\title{
Adaptive Neuro Control of Parallel Hybrid Electric Vehicles
}

\author{
Morteza Mohebbi, Mohammad Farrokhi* \\ Department of Electrical Engineering, \\ Iran University of Science and Technology \\ Narmak, Farjam Street, Tehran, 16846-13114, IRAN \\ ${ }^{*}$ Corresponding Author
}

\begin{abstract}
In this paper, an adaptive control method based on neural networks for controlling parallel hybrid electric vehicles is presented. Power sharing between the internal combustion engine and the electric motor is the key point for efficient driving. The control strategy will be implemented using a neural network. The controller will be designed based on powertrain desired torque and state of charge of batteries. The output of controller adjusts the fuel throttle angle in combustion engine. The main contribution of this paper is development of an on-line controller based on neural networks, which maximizes the output torque of engine while minimizing fuel consumption. In other words, a compromised solution between torque and fuel can be achieved. Also, state of charge of the batteries, which has been estimated by the Ampere-hour counting technique, has been considered. Simulation results show good performance of the proposed controller as compared to off-line-trained adaptive controllers.
\end{abstract}

Keywords: parallel hybrid vehicles; adaptive control; neural networks; fuel minimization.

\section{Introduction}

Since 1990s, a large number of automobile industries have started developing Hybrid Electric Vehicles (HEVs). This is due to the drawbacks inherent in conventional Internal Combustion Engine (ICE) vehicles as well as Electric Vehicles (EVs). In fact, the exhaust emissions of ICE vehicles are the major source of urban pollutions and should be replaced by clean and high efficient vehicles. Although EVs with no emissions attracted the attention of many car industries for a few decades, but many problems like short driving distance, long recharging time of batteries, and high costs, gave strong motives to develop HEVs.

There are two kinds of HEVs: 1) series and 2) parallel. In series HEVs, the powertrain, like EVs, is provided by an electric motor. But, there is a small ICE, which charges batteries when state of charge of them is below certain level. On the other hand, in parallel HEVs, which are the most popular and are considered in this paper, the powertrain is provided by two sources (i.e. by both ICE and electric motor) that are coupled mechanically together. One important issue in parallel HEVs is the amount of torque produced by these powertrain sources in different driving conditions. The contribution of ICE and electric motor in different driving conditions are defined as follows [Husain]:

- In general, when the required torque is more than the maximum torque of ICE, the electric motor covers the torque difference.

- Below a certain velocity of vehicle or when the vehicle stands still, the electric motor provides the entire required torque, since ICEs have low efficiency in these situations.

- When the state of charge of batteries is low, in addition to driving the vehicle, ICE provides the required energy for charging batteries. In this case, electric motor works as generator and charges batteries.

Operation style of each source (i.e. ICE or electric motor) and the amount of their contribution in producing the required torque at any time is determined by a controller. Moreover, this controller should minimize the fuel consumption. But, minimizing fuel consumption could lead to a considerable torque reduction, which may not yield a very pleasant driving. Therefore, in addition to fuel minimization, sometimes it is necessary to maximize the torque as well. That is, although PHEVs have been designed for fuel economy and reducing air pollution, but they must meet some minimum requirements from drivers, especially in cases like car racing, torque maximization plays a very important role.

\subsection{Literatures on Fuel Minimization}

Powel et al. have used a combination of several PID controllers, one for every section of vehicle, due to the highly nonlinear system. But the fuel consumption is relatively high [Powel 1998]. Lyshevski et al. have derived a nonlinear control method based on Lyapunov stability theory. They have achieved smoother control signals as compared to [Powel 1998], but the fuel consumption is still high [Lyshevski et al. 1998] [Lyshevski 1999]. Lin et al. have employed dynamic programming, which a sequential decision making method, to minimize fuel consumption of hybrid vehicles [Lin 2001].

Delprat et al. have used classical optimal control methods to achieve minimum fuel consumption for a given speed cycle [Delprat 2002]. Optimal control methods usually require a precise model of the system. In [??] Schouten et al. and in [??] Cerruto et al. have designed a fuzzy controller with 9 and 27 rules, respectively to control hybrid vehicles. Fuzzy controllers need expert knowledge; and when number of inputs and the corresponding membership functions increase, the curse of dimensionality in fuzzy rules makes the fuzzy controllers not viable. Ippolito et al. have used fuzzy c-means along with genetic algorithms for power flow management (e.g. the contribution of electric motor and 
ICE) in different driving cycle of hybrid electric vehicles [Ippolito 2003]. In their method, there is need for some offline tests from hybrid vehicles; but they have achieved relatively low fuel consumption and smooth simulation results. Berenji and Ruspini have applied Takagi-Sugeno-Kang fuzzy systems to hybrid electric vehicles as multiobjective control problem [Berenji and Ruspini 1996]. They have proposed an algorithm to automatically generate fuzzy rules. A major advantage of their method is the ability of on-line training for controller. Low fuel consumption and smoothness in their results can be observed. Sacks and Cox have proposed neuro-adaptive controllers [Sacks and C. Cox 1999]. Major advantages of neuro-adaptive controllers in vehicles are robustness to different driving and road conditions, change in tire dynamics, and load torques.

\subsection{Literatures on Torque Maximization}

Lee et al. have used fuzzy systems, a fuzzy predictive controller with 9 rules for converting driver's commands to appropriate torques and another fuzzy controller with 25 rules for power balance, in hybrid electric vehicles [Lee and Sul 1998], [Lee et al. 2000], and [Koo et al. 1998]. Maximizing torque alone can lead to high fuel consumption. Moreover, variations in state of charge of batteries are relatively high, which reduces the life time of batteries.

As far as the authors of this paper have seen, all papers in literatures have considered either minimization of fuel consumption, or maximization of torque production.

One way to maximize output torque of PHEVs is to maximize the output torque of ICE. This is mainly due to the fact that PHEVs are designed in such a way that when driver demands high torques, the ICE provides its maximum torque; the remaining required torque is provided by the electric motor.

In this paper, we try to find a compromised solution between fuel consumption and torque production by designing an adaptive neuro controller. The adaptation process is performed on-line, which makes the closed-loop system more robust against disturbances and changes in the system parameters. Moreover, two optimization parameters will be in user's hand to choose appropriate weights ranging from just fuel minimization to only torque maximization.

Simulation results demonstrate very good trade off between fuel minimization and torque maximization. In other words, a good compromised solution has been achieved using the proposed method in this paper. Also a comparison between the on-line and off-line neuro controllers shows the satisfactory performance of the proposed controller, especially when encountering disturbances or changes in driver's demands and road conditions.

In the rest of this paper, section 2 describes the model of the system and an introduction to ADVISOR software that we have used for modelling. Section 3 explains the proposed controller in this paper. Simulation results are presented in section 4 , followed by their comparisons with the simulation results of off-line controllers, in section 5 . Finally, conclusions will be presented in section 6 .

\section{PHEV Model}

In simulations, we will use ADVISOR ${ }^{1} 2002$ software [ADVISOR 1]. This is powerful software for simulation of all kind of vehicles, such as conventional, electrical, series hybrid, and parallel hybrid. It runs in MATLAB/SIMULINK environment. This software was first introduced by $\mathrm{NREL}^{2}$ in 1994 followed by several new versions. Ever since the introduction of this software, it has been used by many researchers in automotive industries and research centres.

ADVISOR consists of several blocks, each representing a particular part of vehicle, such as engine, electric motor, batteries, gearbox, clutch, controllers, and exhaust system. The models of different parts of vehicles in ADVISOR are quasi-static. That is, data have been collected in steady state (e. g. constant torques and speeds), and then have been corrected for transient effects such as the rotational inertia of drive train components [ADVISOR 2]. Also, different driving cycles can be defined in this software.

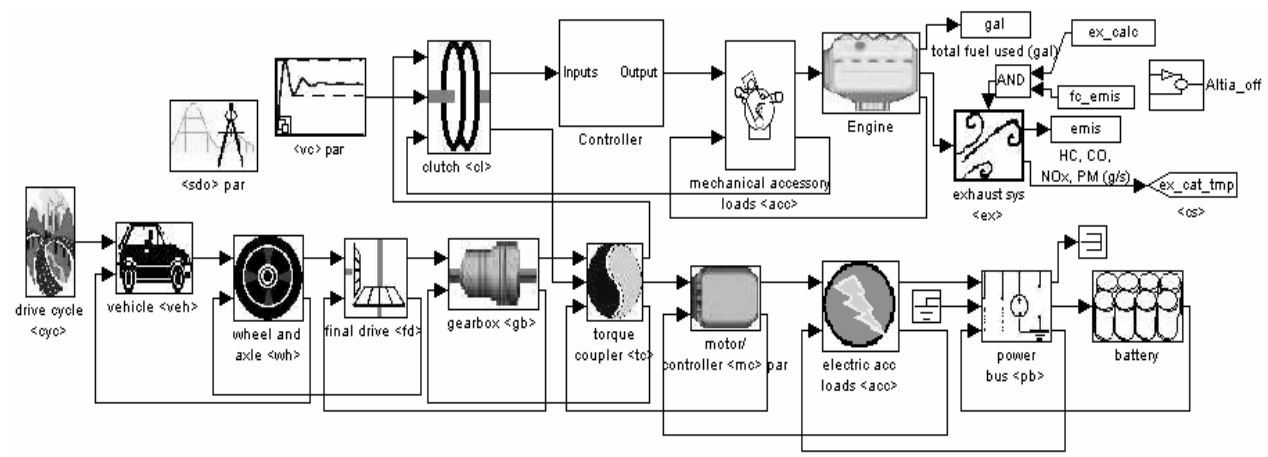

Figure 1 The block diagram of a PHEV and its controller, in ADVISOR.

\footnotetext{
${ }^{1}$ ADvanced VehIcle SimulatOR

2 National Renewable Energy Laboratory
} 


\section{Design of Adaptive Controller}

The controller has two inputs: the load torque and the SOC of the battery pack. The ICE operation point (i.e. the throttle angle of engine) is adjusted based on these inputs. The desired electric motor torque can be calculated as

$$
T_{\text {EM_Desired }}=T_{\text {load }}-T_{\text {ICE_Set }}
$$

where $T_{\text {load }}$ is the load torque, and $T_{\text {ICE_Set }}$ is the desired torque of the ICE, defined by the controller. As it was mentioned before, in order to achieve a compromised solution between three goals (namely, maximizing fuel economy, reducing vehicle output emissions, and maintaining acceptable powertrain performance by maximizing the vehicle output torque), an adaptive Multi-Layer Perceptron (MLP) controller with on-line learning method will be designed. The adaptation law is the back-propagation algorithm to update the weights of the neural network, in such a way to achieve the above goals. The adaptation law for changing weights is

$$
\mathbf{w}(k+1)=\mathbf{w}(k)-\eta \frac{\partial E(k)}{\partial \mathbf{w}(k)}
$$

where $\eta$ is the learning rate and

$$
E(k)=\frac{1}{2} e^{2}(k)
$$

is the instantaneous error, in which we define the error function to train the neural network as

$$
e(k)=\alpha_{1}\left(\left|T_{\mathrm{MAX}}-T\right|\right)+\alpha_{2}\left(\mid \text { fuel }_{\mathrm{MIN}}-\text { fuel } \mid\right)
$$

where fuel is the consumed fuel by ICE per time unit, $T$ is the output torque of ICE, fuel ${ }_{\text {MIN }}$ is the desired fuel consumption designated for fuel minimization, $T_{\mathrm{MAX}}$ is the desired output torque of ICE, chosen to maximize the output torque, and $\alpha_{1}$ and $\alpha_{2}$ are the weighting factors for output torque and fuel consumption, respectively.

The block diagram of the proposed method is presented in Figure 2.

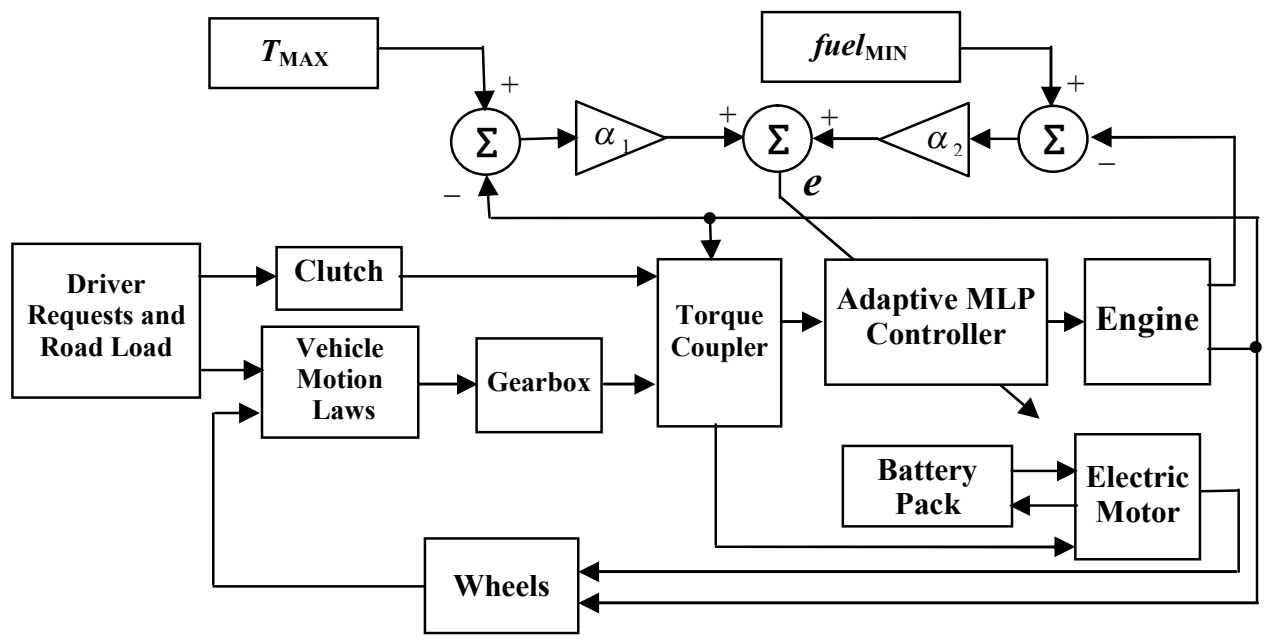

Figure 2 Block diagram of the proposed controller for PHEV.

\section{Simulation Results}

For simulations a Multilayer Perceptron with one hidden layer containing 10 neurons, and the training coefficient $\gamma=0.3$ has been used. Moreover, it has been assumed that $f u e l_{\mathrm{MIN}}=0.14$ (i.e. the ratio of fuel mass to the air mass, consumed by ICE), which is the minimum fuel consumption defined in ADVISOR, and is called fuelmode controller. Also, $T_{\mathrm{MAX}}=45 \mathrm{Nm}$, which is the maximum torque ICE can produce.

In ADVISOR, there are two different control methods: 1) fuel minimization (or fuel-mode) controller for minimizing the fuel consumption and 2) efficiency-mode (eff-mode) controller for maximizing the output torque [ADVISOR 2]. The simulation results will be compared with these two benchmark methods.

As it was mentioned before, there are two weighting factors for adaptive neuro-controller $\left(\alpha_{1}\right.$ and $\left.\alpha_{2}\right)$. In the following sections, first, it is assumed that $\alpha_{1}=\alpha_{2}=1$. That is, both fuel minimization and torque maximization are equally important for the driver. Then, only fuel minimization will be considered (i.e. $\alpha_{1}=0$ and $\alpha_{2}=1$ ). Finally, it is assumed that $\alpha_{1}=1$ and $\alpha_{2}=0$, which stands for output torque maximization of ICE. In other words, in this case, no fuel minimization has been taken into account. This situation can occur in cases like racing. 


\subsection{Fuel Minimization and Torque Maximization $\left(\alpha_{1}=\alpha_{2}=1\right)$}

By selecting $\alpha_{1}=\alpha_{2}=1$, we will get a compromised or optimal solution between fuel minimization and ICE output torque maximization. The desired trajectory for vehicle speed is shown in Figure 3. In this driving cycle, at the instant of $t=20 \mathrm{~s}$, a large acceleration is asked by the driver, followed by pressing the break pedal at $t=295 \mathrm{~s}$. In this cycle, the vehicle covers a distance of $6.4 \mathrm{Km}$ in 329 seconds. The error between the desired speed and the actual speed will be converted to the desired torque using a PI controller. This difference must be compensated by the vehicle powertrain system. Figure 4 shows the error between the desired and the actual vehicle speed, which is in the order of $10^{-11}$.

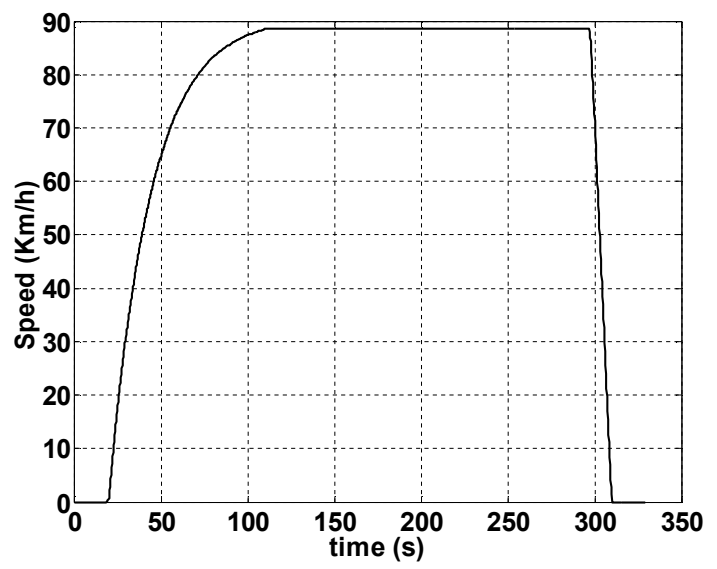

Figure 3 The desired vehicle speed and the actual vehicle speed.

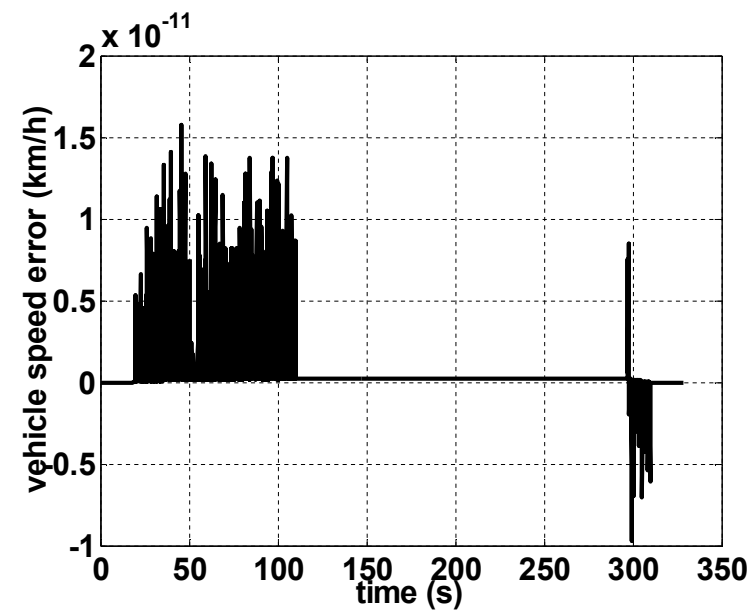

Figure 4 The error between the desired and the actual vehicle speed.

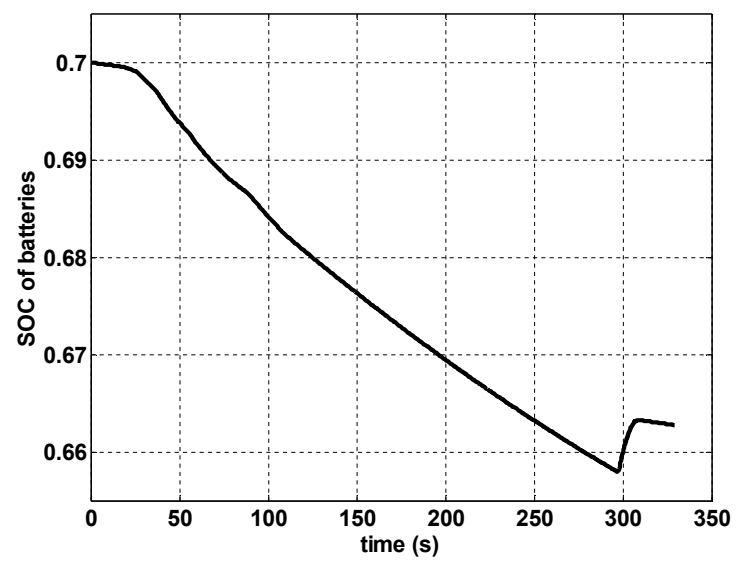

Figure 5 SOC of batteries 


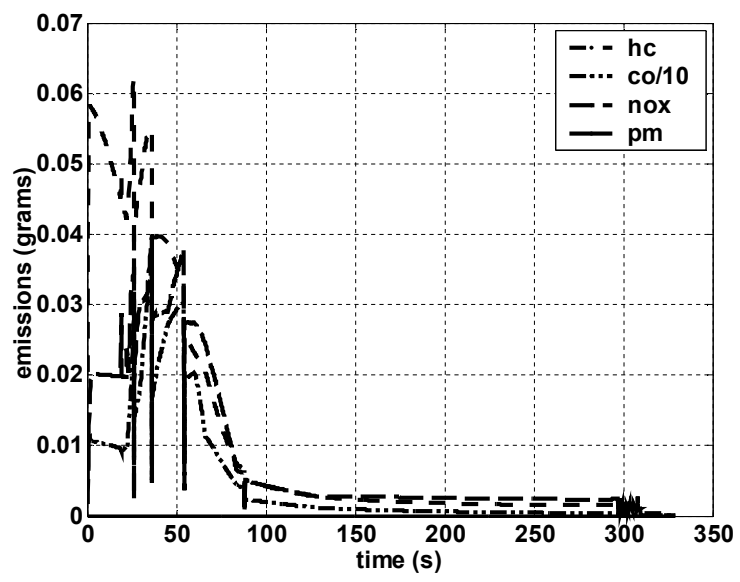

Figure 6 Vehicle emissions for the proposed controller

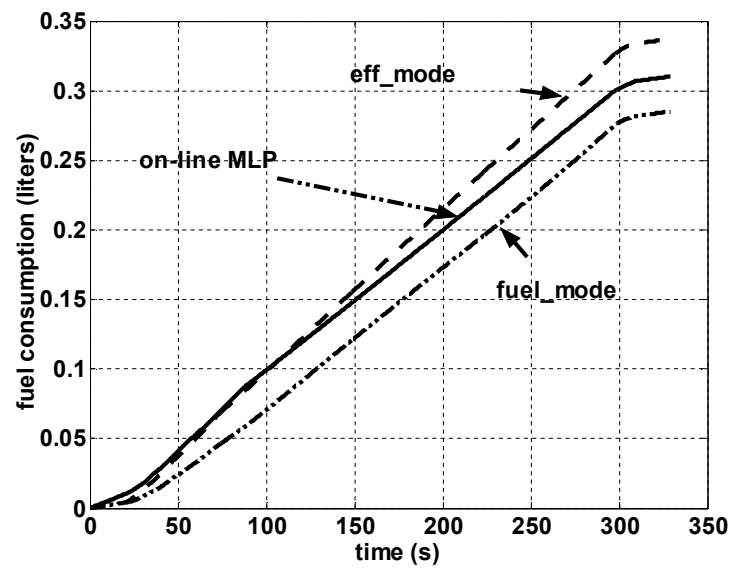

Figure 7 Fuel consumptions

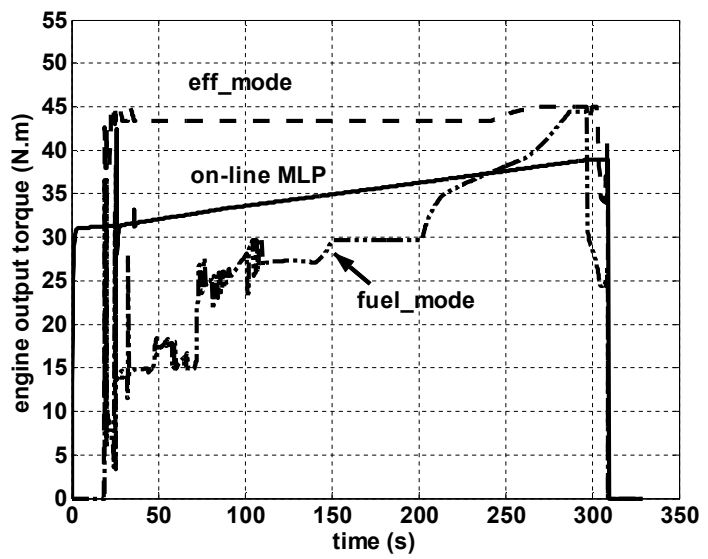

Figure 8 ICE output torques

Table 1 Comparison between the adaptive neuro controller, fuel-mode controller, and eff-mode controller

\begin{tabular}{|c|c|c|c|c|c|}
\hline $\begin{array}{l}\text { Control } \\
\text { Method }\end{array}$ & $\begin{array}{c}\text { Fuel } \\
\text { Consumption } \\
(\mathrm{L} / 100 \mathrm{Km}) \\
\end{array}$ & $\begin{array}{c}\text { Integral of } \\
\text { Torque } \\
(\mathrm{Nms}) \\
\end{array}$ & $\begin{array}{c}\mathrm{HC} \\
(\mathrm{grams} / \mathrm{Km})\end{array}$ & $\begin{array}{c}\mathrm{CO} \\
(\mathrm{grams} / \mathrm{Km})\end{array}$ & $\begin{array}{c}\mathrm{NOx} \\
(\mathrm{grams} / \mathrm{Km})\end{array}$ \\
\hline fuel-mode & 4.4 & 8000 & 0.447 & 2.196 & 0.228 \\
\hline $\begin{array}{c}\text { neuro } \\
\text { controller } \\
\end{array}$ & 4.8 & 10640 & 0.545 & 2.387 & 0.406 \\
\hline eff-mode & 5.2 & 12274 & 0.618 & 2.299 & 0.51 \\
\hline
\end{tabular}


Moreover, the SOC of batteries shows very small changes, resulting in longer life-time of batteries (Figure 5). In addition to that, exhaust emissions for the proposed controller can be observed in Figure 6 .

Comparing the results of adaptive neuro controller with the results of two control modes in ADVISOR (i.e. fuelmode and eff-mode) reveals a good performance for the proposed controller. The fuel consumptions for neuro controller and two ADVISOR controllers are shown in Figure 7. Also, Figure 8 shows the ICE output torques. As it is obvious from this Figure, adaptive controller exhibits smoother output torque, which gives less tension to the engine parts. Table 1 presents fuel consumptions, integral of ICE output torques, and vehicle emissions, for different controllers.

\subsection{Fuel Minimization $\left(\alpha_{1}=0\right.$ and $\left.\alpha_{2}=1\right)$}

Ignoring the effect of torque maximization in performance measure (3), a solution based only on fuel minimization will be obtained. The absolute error between the fuel consumption and the minimum fuel requirement is shown in Figure 10. Moreover, as Figure 11 shows, the fuel consumption for the proposed method in this paper almost coincides with the optimal fuel-mode controller in ADVISOR, meaning that the adaptive neuro controller can find an optimal solution in every case, chosen by the driver. Table 2 shows fuel consumptions, integral of ICE output torques, and vehicle emissions for different controllers. One observation from this table is that, although fuel consumption by the neuro controller is slightly higher than that of fuel-mode controller, but the produced torque, and $\mathrm{HC}$ and $\mathrm{NOx}$ emissions are better than those of fuel-mode controller.

\subsection{Torque Maximization $\left(\alpha_{1}=1\right.$ and $\left.\alpha_{2}=0\right)$}

Now, the goal of the optimization problem is to maximize the ICE output torque. That is, no fuel minimization will be taken into account. This can be achieved by choosing weighting factors in (4) as $\alpha_{1}=1$ and $\alpha_{2}=0$. This case is important for driving in special situations, such as racing, where fast accelerations are needed. Figure 12 shows the absolute of error between the ICE torque and maximum ICE torque. The ICE output torque for different controllers has been shown in Figure 13. As this Figure shows, the ICE output torque for the proposed controller is even better than the eff-mode controller. Moreover, and more importantly, the torque produced by the neuro controller is smoother that that of eff-mode controller or fuel-mode controller. Table 3 shows the fuel consumption, the integral of ICE torque, and the amount of vehicle emissions. As this table shows, adaptive neuro controller provides more output torque than eff-mode. Moreover, the emissions are almost the same for the proposed controller and the eff-mode, even though MLP controller consumes slightly higher fuel.



Figure 10 Error between the fuel consumption and the minimum fuel requirement for the neuro controller.

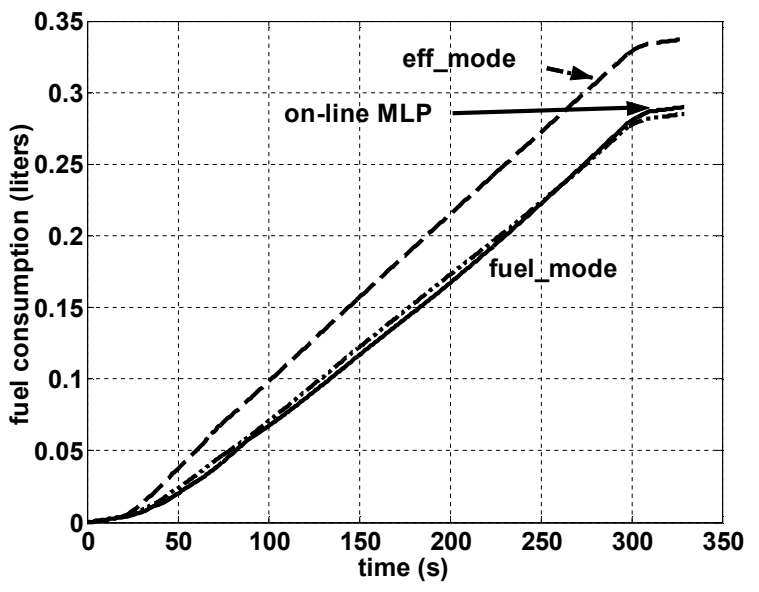

Figure 11 The fuel consumptions 
Table 2 Summary of fuel consumptions, integral of ICE output torques, and the vehicle emissions, when the adaptive neuro controller performs only fuel minimization

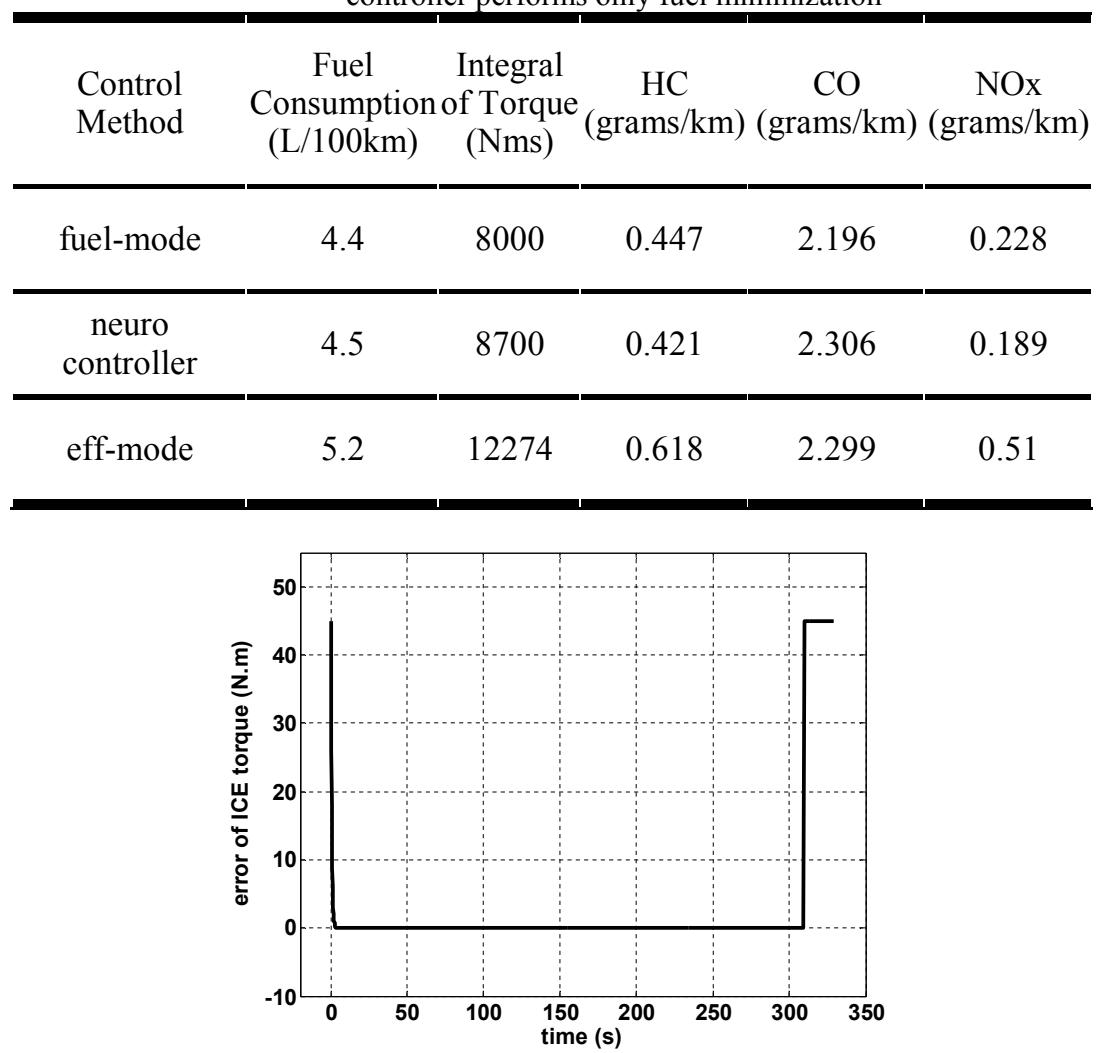

Figure 12 Error between the ICE torque and maximum ICE torque for neuro controller, when the vehicle is carrying $1200 \mathrm{~kg}$ load.

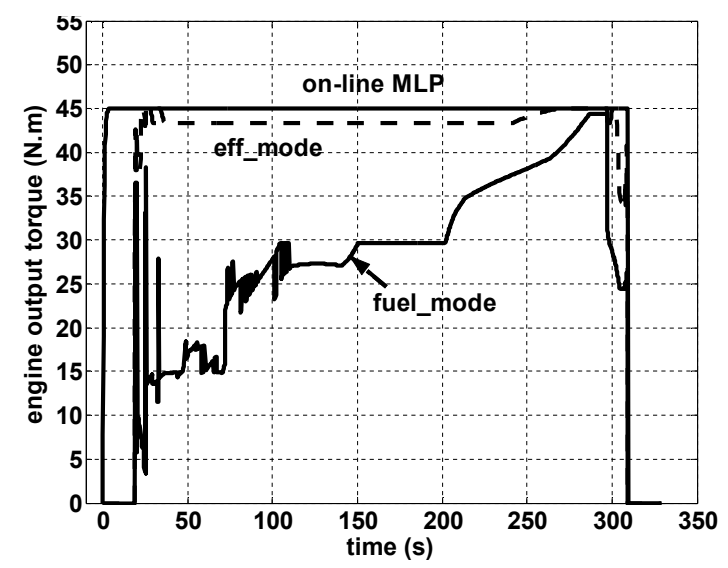

Figure 13 The ICE output torques

Table 3 Summary of fuel consumptions, integral of ICE output torques, and vehicle emissions, when the adaptive neuro controller performs only torque maximization

\begin{tabular}{cccccc}
$\begin{array}{c}\text { Control } \\
\text { Method }\end{array}$ & $\begin{array}{c}\text { Fuel } \\
\text { Consumption } \\
(\mathrm{L} / 100 \mathrm{~km})\end{array}$ & $\begin{array}{c}\text { Integral of } \\
\text { Torque } \\
(\mathrm{Nms})\end{array}$ & $\begin{array}{c}\mathrm{HC} \\
(\mathrm{grams} / \mathrm{km})\end{array}$ & $\begin{array}{c}\mathrm{CO} \\
(\mathrm{grams} / \mathrm{km})\end{array}$ & $\begin{array}{c}\mathrm{NOx} \\
(\mathrm{grams} / \mathrm{km})\end{array}$ \\
\hline fuel-mode & 4.4 & 8000 & 0.447 & 2.196 & 0.228 \\
\hline $\begin{array}{c}\text { neuro } \\
\text { controller }\end{array}$ & 5.6 & 14000 & 0.599 & 2.228 & 0.562 \\
\hline eff-mode & 5.2 & 12274 & 0.618 & 2.299 & 0.51 \\
\hline \hline
\end{tabular}




\subsection{Load Increase}

In this section we evaluate performance of the proposed controller and two controllers in ADVISOR against load increase. It is assumed that the vehicle is carrying a load equal to $1200 \mathrm{~kg}$. Figures 14-18 show the SOC of batteries, fuel consumption, and ICE output torques. These Figures also have been summarized in Table 5. The adaptive neurocontroller exhibits smoother torque curve as compared to fuel-mode controller and consumes less fuel as compared to eff-mode controller.

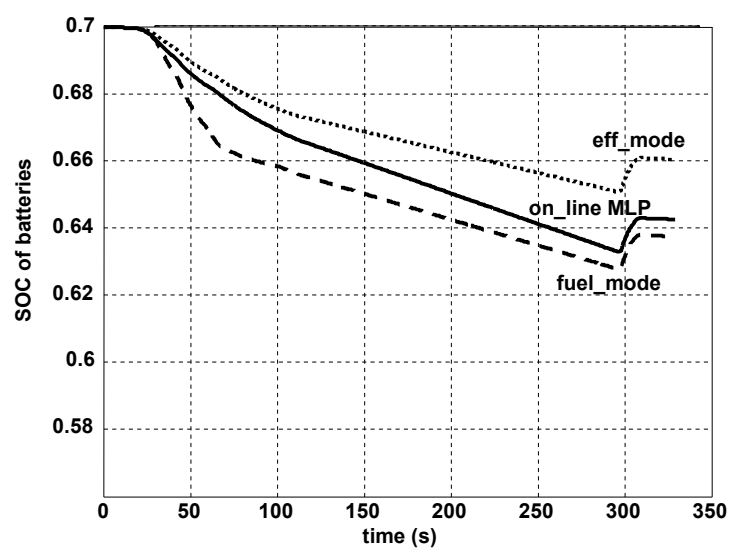

Figure 14 SOC of batteries

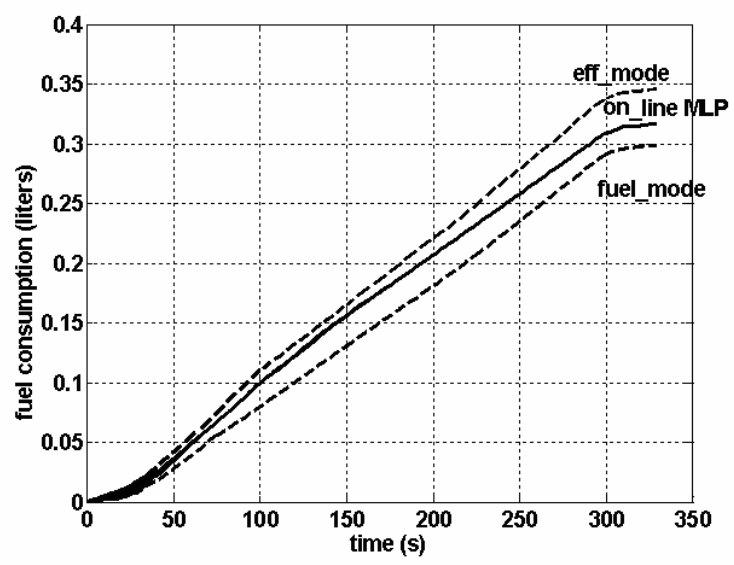

Figure 15 Fuel consumptions

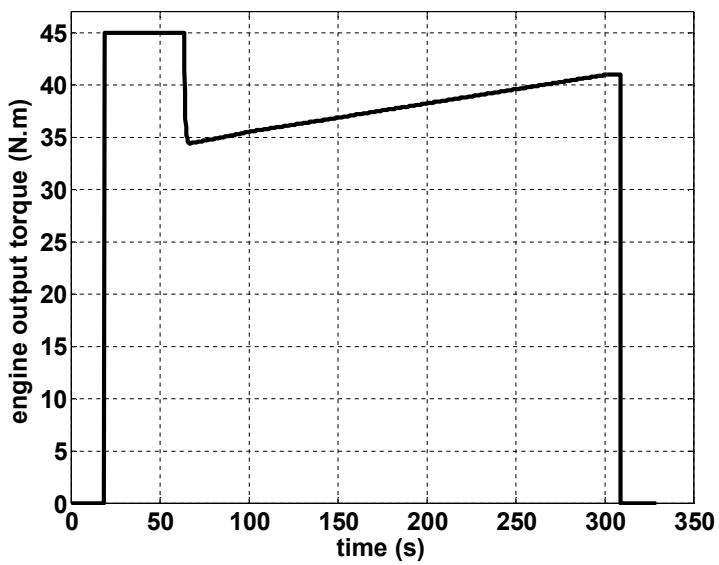

Figure 16 The ICE torque for adaptive neuro-controller 


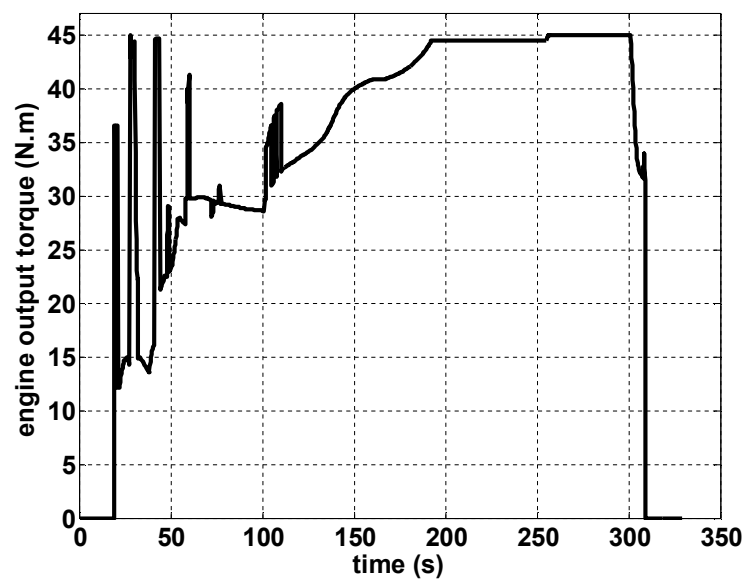

Figure 17 The ICE torque for fuel-mode controller



Figure 18 The ICE torque for eff-mode controller

Table 5 Fuel consumptions and the integral of ICE torques, for $1200 \mathrm{~kg}$ load increase in vehicle cargo weight

\begin{tabular}{ccc}
$\begin{array}{c}\text { Control } \\
\text { Method }\end{array}$ & $\begin{array}{c}\text { Fuel Consumption } \\
(\mathrm{L} / 100 \mathrm{~km})\end{array}$ & $\begin{array}{c}\text { Integral of Torque } \\
(\mathrm{Nms})\end{array}$ \\
\hline fuel-mode & 5.3 & 10840 \\
\hline neuro controller & 6 & 11305 \\
\hline eff-mode & 7.1 & 13000 \\
\hline
\end{tabular}

\subsection{Speed Profile for Cities}

Previous simulations were performed for speed profile shown in Figure 3. Now, the proposed controller will be tested for a different speed profile, which has been shown in Figure 19 and can be considered as a vehicle speed profile for cities. In this driving cycle, the vehicle will cover $1.9 \mathrm{~km}$ distance in 600 seconds.

The fuel consumption by three controllers is shown in Figure 20. Also, the ICE output torques are shown in Figures 21 to 23. Table 6 summarizes these Figures. Comparing adaptive neuro controller with fuel-mode controller shows that the proposed controller consumes $7.7 \%$ more fuel, but produces $64 \%$ more torque. Also, comparing with effmode controller it can be seen that the neuro controller consumes $20 \%$ less fuel, and generates $18 \%$ less torques. Based on these, one can conclude that the adaptive neuro controller can find an optimal solution between fuel consumption and torque generation. Moreover, the neuro controller produces a torque profile with less number of maximums and minimums, as it is shown in Figure 21, which produces less stress and wears on mechanical parts of vehicle. 


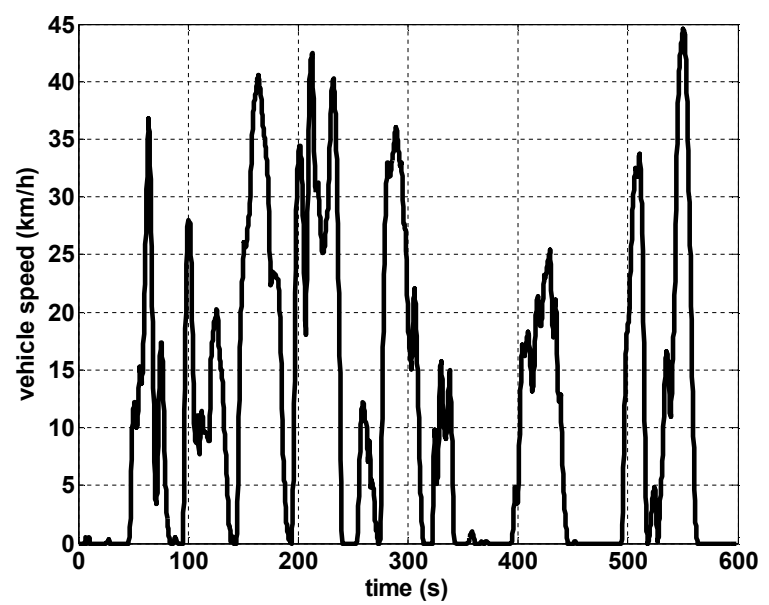

Figure 19 Vehicle speed cycle, similar to a city-speed profiles

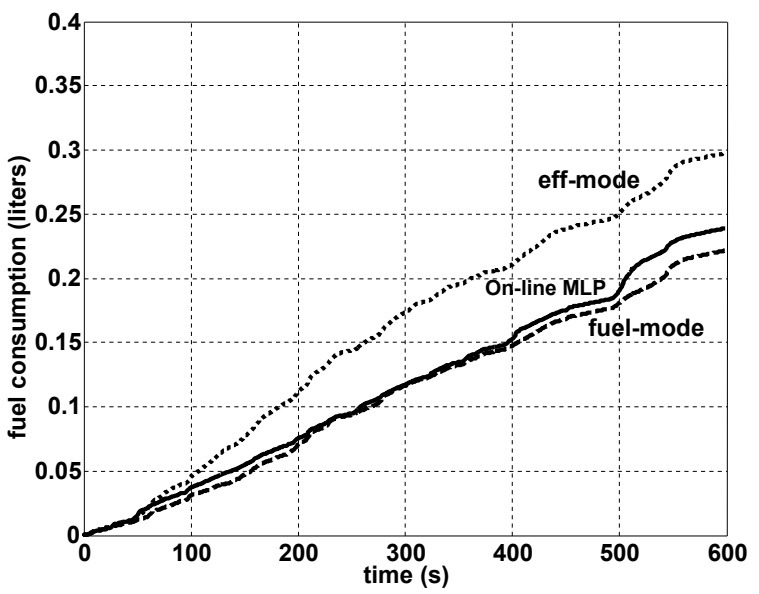

Figure 20 Fuel consumptions

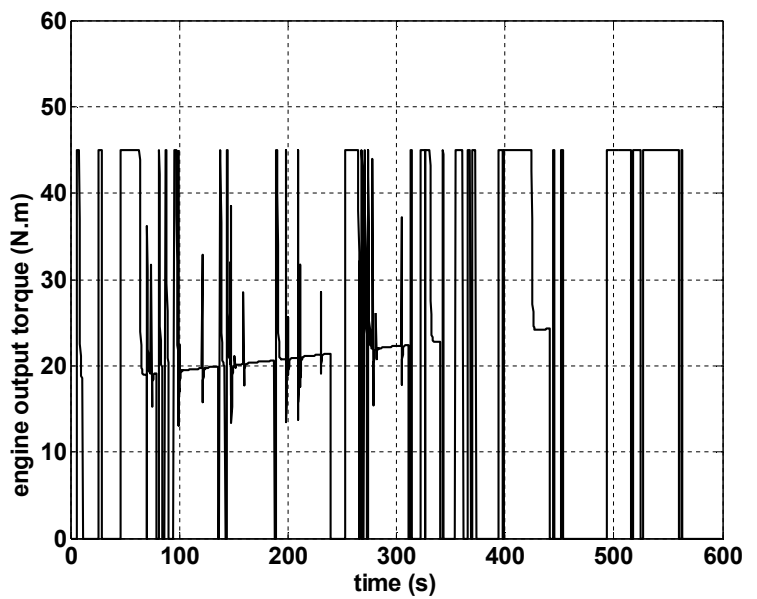

Figure 21 The ICE torque for the proposed adaptive neuro controller 


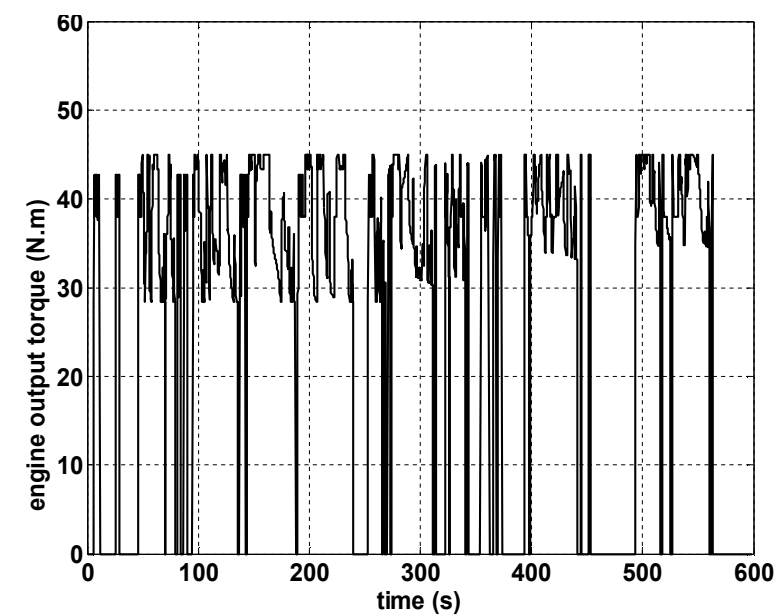

Figure 22 The ICE torque for the eff-mode controller

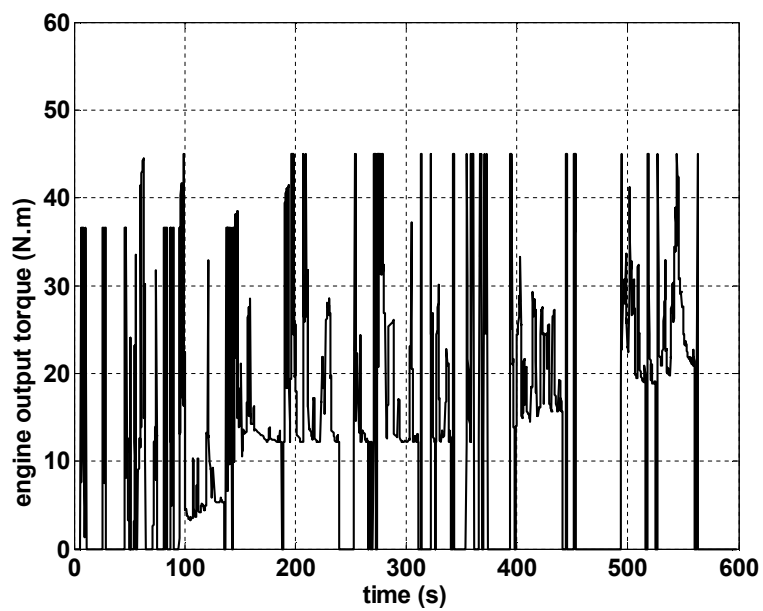

Figure 23 The ICE torque for the fuel-mode

Table 6 Fuel consumptions and Integral of ICE torques, for a driving cycle similar to cities speed profile.

\begin{tabular}{ccc}
\hline $\begin{array}{c}\text { Control } \\
\text { Method }\end{array}$ & $\begin{array}{c}\text { Fuel Consumption } \\
(\mathrm{L} / 100 \mathrm{~km})\end{array}$ & $\begin{array}{c}\text { Integral of Torque } \\
(\mathrm{Nms})\end{array}$ \\
\hline fuel-mode & 11.7 & 7500 \\
\hline neuro controller & 12.6 & 12280 \\
\hline eff-mode & 15.7 & 15000 \\
\hline
\end{tabular}

\section{Conclusions}

In this paper a control method for finding an optimal solution between fuel minimization and torque maximization was proposed for parallel hybrid electric vehicles. For this reason, an adaptive neuro controller was designed and used in ADVISOR software. Simulation results were compared with two different control strategies in ADVISOR, one for fuel minimization and the other one for torque maximization. The proposed method provides very good solutions for different speed cycles as compared with these two controllers in ADVISOR. That is, the neuro controller finds a compromised solution. Moreover, it was shown in simulations that the proposed controller is robust against changes in system parameters, such as load increase. In addition to that, the exhaust emissions were acceptable and almost as low as the fuel-mode in ADVISOR. In the continuation of this research we proposed to make some analytical work in the proposed controller, such as conditions for convergence of adaptive weights in neuro controller. 


\section{References}

Husain, I. (2003) Electric and Hybrid Vehicles: Design Fundamentals, CRC Press.

Mohebbi, M., Charkhgard, M. and Farrokhi, M. (2005) 'Optimal neuro-fuzzy control of parallel hybrid electric vehicles', IEEE Vehicle Power and Propulsion Conference, Chicago, Illinois, USA, pp. 252-256.

Schouten, N. J., Salman, M. A. and Kheir, N. A. (2003) `Energy management strategies for parallel hybrid vehicles using fuzzy logic', Control Engineering Practice, Vol. 11, pp. 171-177.

Cerruto, E., Consoli, A., Raciti A. and Testa, A. (1994) 'Energy flows management in hybrid vehicles by fuzzy logic controller', 7th Mediterranean Conference on Electrotechnical, pp.1314 - 1317.

Lee, H. D. and Sul, S. (1998) 'Fuzzy-logic-based torque control strategy for parallel-type hybrid electric vehicle', IEEE Transactions on Industrial Electronics, Vol. 45, No. 4, pp. 625 - 632.

Lee, H.D., Koo, E.S., Sul, S., Kim, J., Kamiya, M., Ikeda, H., Shinohara, S. and Yoshida, H. (2000) 'Torque control strategy for a parallel-hybrid vehicle using fuzzy logic', IEEE Industry Applications Magazine, Vol. 6, No. 6, pp. 33 - 38.

ADVISOR 2002 software, http://www.ctts.nrel.gov

National Renewable Energy Laboratory. ADVISOR Documentation. Golden Co. [Online]. Available: http://www.ctts.nrel.gov/analysis/

Puleston, P. F., Spurgeon, S. and Lu, X., (2000) 'A nonlinear sliding-mode control framework for engine speed control', International Symposium of Mathematical Theory of Networks and Systems, Perpignan, France.

Powell, B. K. and Pilutti, T. E. (1994) 'A range extender hybrid electric vehicle dynamic model', IEEE Conference on Decision and Control, Vol. 3, pp. $2736-2741$.

Powell, B. K., Bailey, K. E. and Cikanek, S. R. (1998) 'Dynamic modelling and control of hybrid electric vehicle powertrain systems', IEEE Control Systems Magazine, Vol. 18, No. 5, pp.17 - 33.

Lyshevski, S. E. (1999) 'Diesel-electric drivetrains for hybrid-electric vehicles: new challenging problems in multivariable analysis and control', IEEE International Conference on Control Applications, Vol.1, pp.840-845.

Lyshevski, S. E. and Yokomoto, C. (1998) 'Control of hybrid-electric vehicles', American Control Conference, Vol.4, pp.21482149.

Lin, C. C., Kang, J. M., Grizzlq, J. W. and Peng, H. (2001) 'Energy management strategy for a parallel hybrid electric truck', American Control Conference, Vol. 4, pp. 2878-2883.

Delprat, S., Guerra, T. M. and Rimaux, J. (2002) 'Control strategies for hybrid vehicles: optimal control', IEEE Vehicular Technology Conference, Vol. 3, pp. 1681-1685.

Ippolito, L., Loia, V. and Siano, P. (2003) 'Extended fuzzy c-means and genetic algorithms to optimize power flow management in hybrid electric vehicles', IEEE Conference on Control Applications, Vol. 1, pp. 115-119.

Berenji, H. R. and Ruspini, E. H. (1996) 'Experiments in multiobjective fuzzy control of hybrid automotive engines', IEEE International Conference on Fuzzy Systems, Vol. 1, pp. 681- 686.

Sacks R. and Cox, C. (1998) 'Design of an adaptive control system for a hybrid electric vehicle', IEEE SMC Conference, Vol. 6 , pp. 1000-1005.

Koo, E. S., Lee, H. D., Sul, S. K. and Kim, J. S. (1998) 'Torque control strategy for a parallel hybrid vehicle using fuzzy logic', IEEE Industry Applications Conference, Vol. 3, pp. 1715-1720.

Piller, S., Perrin, M. and Jossen, A. (2001) 'Methods for state-of-charge determination and their applications', Journal of Power Sources, No. 96, pp. 113-120.

Farrokhi, M. and Mohebbi, M. (2005) 'Optimal fuzzy control of parallel hybrid electric vehicles', International Conference on Control, Automation and Systems, Kintex, Gyeonggi-Do, South Korea. 